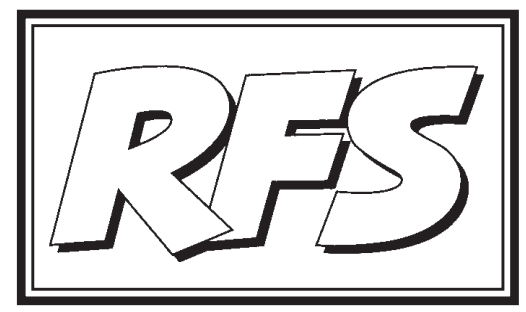

Revista de Fomento Social, 61 (2006), 361-392

\title{
Pensar la integración de los inmigrantes: la sociedad española al comienzo del siglo XXI
}

Julio L. MARTÍNEZ MARTÍNEZ, SJ

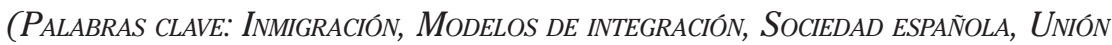
EUROPEA.

KEY WORDS: INMIGRATION, MODELS OF INTEGRATION, SPANISH SOCIETY, EUROPEAN UNION)

La primera vez que la integración me resonó de un modo especial fue en el 2001 de labios de una religiosa alemana en un Congreso sobre las migraciones contemporáneas en Berlín del que Revista de Fomento Social dio, en su momento, cumplida cuenta ${ }^{1}$. Recuerdo que para mí fue un descubrimiento oírle decir que el sujeto de la integración no eran los inmigrantes sino la sociedad.

1 Revista de Fomento Social n. 224 (octubre-diciembre 2001). 
Desde entonces he venido prestando atención a los diferentes usos de ese término. Y me he dado cuenta de que lo que pensamos sobre la integración en relación a los inmigrantes tiene que ver con lo que pensamos en relación a los contextos sociales, a veces muy cercanos, en los que nos movemos, pues, en realidad, la inmigración plantea algunas cuestiones originales pero nada totalmente nuevo y no pertinente a otros temas y ámbitos.

\section{Los perfiles sociodemográficos de un cambio espectacular}

En los últimos siete años, la realidad demográfica española ha sufrido un cambio que no conoce precedentes. De hecho, en 1998, primer año en el que puede accederse en España a estadísticas fiables sobre nacionales de otros países, los extranjeros procedentes de países en vías de desarrollo apenas alcanzaban un 1\% (322.623) sobre el total de residentes en el país (casi 40 millones); en el año 2005 este porcentaje rozaba el 7\%: casi 3 millones de algo más de 44 (Gráfico 1). El porcentaje de población extranjera empadronada alcanza el 8,5\%, lo cual supone 3.730 .610 personas $^{2}$, cifra que evidentemente, además de los extranjeros procedentes de países en desarrollo, tiene en cuenta los procedentes de países desarrollados.

\section{GRÁFICO 1: Evolución de la población extranjera empadronada. Datos a 1 de enero de cada año. 1996-2005}

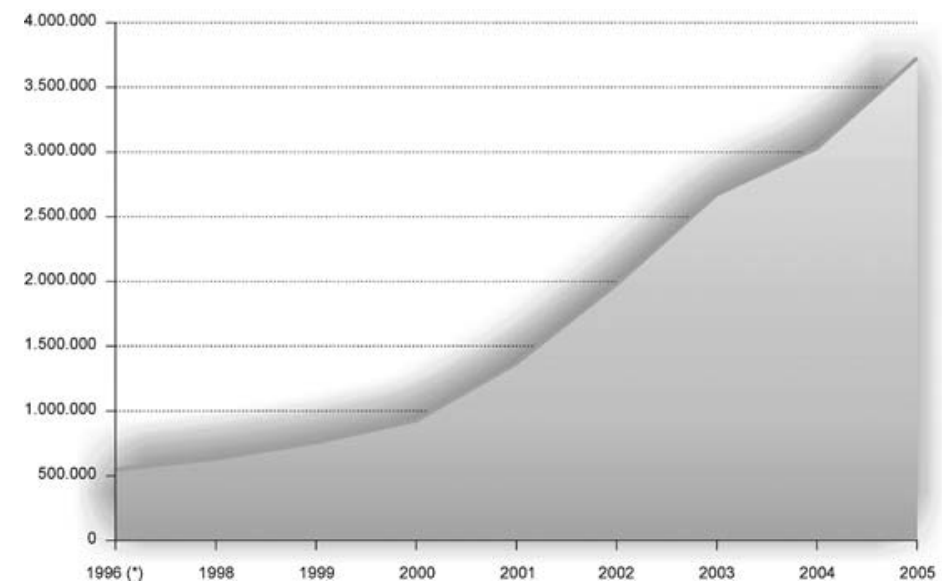

Fuente: Elaboración propia a partir de INE, Padrón municipal de habitantes, varios años.

2 El INE facilitó nuevos datos a 25 de julio de 2006, según los cuales la cifra de extranjeros 
Los datos aportados por EUROSTAT señalan a España como el Estado europeo de mayor saldo neto inmigratorio en los últimos años, con casi un $23 \%$ del total, por encima de Italia (21\%), de Alemania (16\%) y del Reino Unido $(11 \%)^{3}$. Y, en números absolutos, España también se sitúa a la cabeza de Europa, por detrás de Alemania (7,3 millones de inmigrantes), pero delante de otros países tradicionalmente receptores, como Francia ( 3,2 millones) o el Reino Unido (2,7 millones).

\section{CUADRO 1: Población extranjera empadronada por nacionalidad. Valor absoluto y porcentaje. 2005}

\begin{tabular}{lcc}
\hline & Absoluto & Porcentaje \\
\hline Unión Europea (25) & 774.953 & 20,8 \\
\hline Marruecos & 511.294 & 13,7 \\
\hline Ecuador & 497.799 & 13,3 \\
\hline Rumanía & 317.366 & 8,5 \\
\hline Colombia & 271.239 & 7,3 \\
\hline Argentina & 152.975 & 4,1 \\
\hline Bolivia & 97.947 & 2,6 \\
\hline Bulgaria & 93.037 & 2,5 \\
\hline China & 87.731 & 2,4 \\
\hline Perú & 85.029 & 2,3 \\
\hline Ucrania & 65.667 & 1,8 \\
\hline República Dominicana & 57.134 & 1,5 \\
\hline Resto de nacionalidades & 718.439 & 19,3 \\
\hline Total & 3.730 .610 & $\mathbf{1 0 0}$ \\
\hline
\end{tabular}

Fuente: Elaboración propia a partir de INE, Padrón municipal de habitantes a 1 de enero de 2005, en www.ine.es.

empadronados ascendía en esa fecha a 3.884.600, de los cuales comunitarios eran 916.100 y no comunitarios 2.968.000. La diferencia de cruzar el número de extranjeros empadronados no comunitarios empadronados y extranjeros que tienen permiso o tarjeta arroja la cantidad de 1.010.409 personas que estarían en situación irregular.

3 Cf. EUROSTAT (2004), First demographic estimates for 2003. Statistics in focus, Population and social conditions. 
En el cuadro anterior se detalla el peso porcentual de cada nacionalidad en el total de la población extranjera empadronada en España al comenzar 2005. Sólo el 20,8\% de los extranjeros residentes en España en esa fecha pertenecía a la Unión Europea. Si, además, se analiza la evolución temporal de la composición interna de la población extranjera, que se muestra tanto porcentualmente como en términos absolutos en el Gráfico 2, destaca con nitidez el hecho de que la mayor parte de los efectivos que España recibe proceden, hoy por hoy, de países en desarrollo.

\section{GRÁFICO 2: Distribución de la población inmigrante}

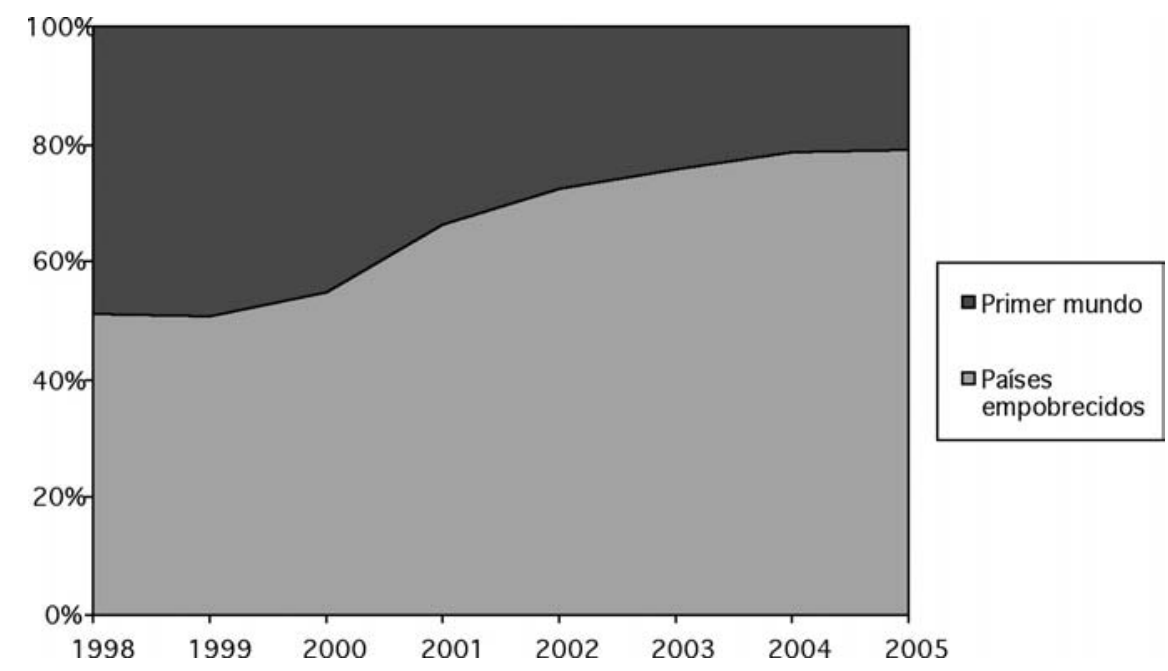

Fuente: Elaboración propia a partir de INE, Ibidem.

Dada la escasa representatividad actual de individuos procedentes del primer mundo en nuestro país, queda patente el mayoritario carácter económico de la inmigración que recibe España ${ }^{4}$. De los inmigrantes económicos,

4 Con todo, esto cada vez hay que matizarlo más, pues algunos países con índices de desarrollo muy inferiores a la UE15 proveedores de emigrantes a España han pasado a formar parte de la UE25, lo que supone que algunos inmigrantes de la UE puedan ser considerados como inmigrantes económicos. La previsible quinta ampliación acogería nacionalidades como la rumana o la búlgara que, en este momento, configuran ya colonias numéricamente muy relevantes dentro de la población extranjera. 
algo más de la mitad (54,1\%) corresponden a Marruecos, Ecuador, Rumanía y Colombia. Ésta es la fotografía del momento actual. Pero, según la evolución del mosaico de nacionalidades que componen el espectro inmigratorio a España, previsiblemente evolucionará con el tiempo. Actualmente, se aprecian aumentos significativos en colectivos como el búlgaro o el boliviano, hasta ahora prácticamente desconocidos.

Por lo que se refiere a la distribución de la población extranjera dentro de España, las comunidades autónomas con un mayor peso porcentual de ciudadanos extranjeros son Baleares (con casi un 16\%), Madrid (más del $13 \%$ ), Comunidad Valenciana y Murcia (entre el 12\% y el 13\%) y Cataluña y Canarias (que superan el 11\%). Si nos fijamos en la distribución geográfica del total de la población extranjera por comunidad autónoma, la situación varía sensiblemente: Cataluña, Madrid, Comunidad Valenciana y Andalucía absorben el 69,2\% de los extranjeros empadronados en España; si se añade Murcia, suman casi las tres cuartas partes de este colectivo.

Se observa una ligera masculinización de la población extranjera-53,4\% de hombres sobre el 46,6\% de mujeres (este dato se matiza al desagregarla por nacionalidades)-, mientras que entre la población con nacionalidad española el porcentaje de mujeres es del $51 \%$ frente al $49 \%$ de hombres.

Por lo que se refiere a la pirámide de edad, el $64,6 \%$ de los extranjeros se encuentra en el intervalo comprendido entre los 16 y los 44 años y el 15,4\% entre los 44 y los 65 años. Es decir, un 80\% del total está en edad de trabajar. Esta afirmación queda confirmada por el pequeño porcentaje de mayores de 65 años (4,8\%). Por último, el 15,1\% del total de la población extranjera empadronada en España tiene menos de 16 años. Dicho de otra manera, el más de medio millón largo de niños extranjeros empadronados a finales de 2004 supone el 8,4\% de la población total menor de 16 años que hay en España. Este dato muestra que los procesos de reunificación familiar se van consolidando paralelamente a la maduración del proyecto migratorio.

Más allá de estas ineludibles cuestiones de índole cuantitativa, apreciamos que la particular relevancia del fenómeno viene dada, sobre todo, por la cualidad de esta inmigración: la heterogeneidad de los colectivos inmigrantes -distintas nacionalidades, orígenes socio educativos y económicos diversos-, los grupos de edad que predominan -población joven en edad de trabajar, niños y jóvenes en el sistema educativo- y el virtual proyecto de permanencia-familias inmigrantes-. Estos tres aspectos marcan la necesaria interacción de los inmigrantes con la sociedad de acogida. 


\section{2. ¿De qué hablamos cuando hablamos de integración?}

Desde luego, a estas alturas a nadie le extraña ya que, al referirnos a la inmigración, dejemos de lado la repetida frase de estos últimos años de que España ha dejado de ser un país de emigración para convertirse en uno de inmigración: ya existe la España inmigrante. En los últimos cinco años, tras la consolidación de una inmigración de asentamiento y de raíz fundamentalmente económica, el número de inmigrantes ha alcanzado cifras antes insospechadas y su diversificación es cada vez mayor: se está iniciando así la construcción social de la España inmigrante, una etapa que se inscribe dentro del ciclo de desarrollo de la globalización de la sociedad y de la economía.

Desde hace ya un par de décadas, en Europa hablar de inmigración lleva a hablar de integración, cuestión que es ya casi obligada al abordar cualquier tema de la vida social en sus múltiples expresiones. Para que se produzca la integración hace falta incorporar al inmigrante en la sociedad, es decir, superar el modelo de que el inmigrante no es otra cosa que un Gastarbeiter, o sea, trabajador huésped, para estar en el país receptor temporalmente. Como su nombre indicia, al Gastarbeiter no habría que favorecerle la integración social sino el "encaje social" durante el tiempo de duración de sus contratos de trabajo y de las necesidades que pueden llevar a contratarles. Obviamente, el verbo "encajar" sustituye aquí a "integrar".

Las más recientes definiciones de la integración dadas en el seno de la Unión Europea ${ }^{5}$ la entienden como un proceso de doble sentido basado en los derechos recíprocos y las obligaciones correspondientes de los nacionales de terceros países con residencia legal y la sociedad de acogida. Por su parte, el Diccionario de la lengua española, fuente a la que siempre conviene acudir cuando se trata de conocer significados precisos de palabras, define integración como "la unión en un todo de las partes que lo forman". Aun cuando la definición parece no encerrar más complicaciones, sin embargo, no siempre es fácil saber de qué hablamos cuando utilizamos la palabra integración. Una cosa que de las dos definiciones mencionadas ("proceso de doble sentido" y "unión de las partes en un todo") se infiere con bastante claridad es que la integración no puede ser sólo de los que llegan a una sociedad. Y eso ya supone un contraste importante a muchos usos que se hacen de nuestro término, empezando por el título que he puesto a este artículo.

Se impone, pues, hacer un acercamiento crítico a la cuestión.

5 Véase la parte final de la Comunicación de la Comisión al Consejo, al Parlamento Europeo, al Comité Económico y Social Europeo y al Comité de las Regiones sobre inmigración, integración y empleo, COM (2003) 336. 


\section{Algunas dificultades con el concepto de integración}

Una primera dificultad tiene que ver con la unilateralidad, relacionada con el hecho de que, en la práctica, los que tienen que integrarse son los que llegan. La otra vía de la integración -la de la sociedad en general-suele olvidarse; y en ella ha de insistirse para conceptuar la integración de manera más acabada.

Una segunda cuestión se refiere a la necesidad de las comparaciones para poder decir si se da o no integración. En el caso de los inmigrantes se trata de comparar los procesos que viven los no nacidos en el país de acogida y que no son ciudadanos, con los autóctonos nacionales o con los nacionalizados nacidos en otros países, e incluso con los inmigrantes que se encuentran en situación irregular, etc. El hecho es que sin comparar es difícil hablar de integración.

Una tercera dificultad puede encontrarse en que, si la integración es un proceso con diferentes fases, de doble dirección, con ámbitos y dimensiones, con políticas y prácticas, entonces no puede ser entendida como un estado, o de modo estático.

En cuarto lugar, las dificultades con la integración provienen también de los muchos ámbitos que abarca: casi todos los de toda la vida cotidiana de una persona o grupo y durante el transcurso de mucho tiempo (por eso es un proceso, y no un estado que se logra en un momento dado). Y las preguntas aquí son muchas: ¿hay unos ámbitos más importantes que otros, más decisivos que otros?; y, si los hay, ¿quién establece la jerarquía entre ellos?: ¿los teóricos?, ¿los investigadores?, ¿los propios inmigrantes?, ¿todos conjuntamente?

La quinta dificultad estriba en que la integración veces se define como una de las estrategias de de la aculturación y la adaptación, estableciendo sus diferencias con el concepto de asimilación, de segregación o de marginación; y en otras presentaciones integración es la categoría más general siendo la asimilación o la segregación modos diversos de especificarse. Para ilustrar la primera vía nos sirve la aproximación de J. W. Berry ${ }^{6}$, cuyo enfoque concibe la integración como contrapuesta a la asimilación, a la segregación y a la marginación, en función de la confluencia (o no) de dos variables que en el siguiente cuadro se exponen:

6 Cf. J. W. BerRy (1992), "Acculturation and Adaptation in a New Society", International Migration 30 (Special Issue: "Migration and Health in the 1990s"), pp. 69-85. 


\section{CUADRO 2}

\begin{tabular}{|c|c|c|}
\hline \multirow{2}{*}{$\begin{array}{c}\text { Adquisición de nueva } \\
\text { cultura }\end{array}$} & \multicolumn{2}{|c|}{ Conservación de la identidad de origen } \\
\cline { 2 - 3 } & SI & NO \\
\hline SI & INTEGRACIÓN & ASIMILACIÓN \\
\hline NO & SEGREGACIÓN & MARGINACIÓN \\
\hline
\end{tabular}

Fuente: Elaboración propia.

Una sexta dificultad estriba en que las formas prácticas de integración -tanto las administrativas como las de la intervención y las de los propios inmigrantes- son distintas según el modelo político de integración que formule cada Estado, e incluso difieren en función de algunas características de las sociedades de acogida. Entre ellas destacamos las siguientes:

- Actitudes hacia la diversidad. Evidentemente, la vivencia de la diversidad por parte de los distintos Estados estará condicionada por su pasado histórico, por la existencia de lazos previos -pasado colonialista-con determinadas comunidades de inmigrantes, por el sentimiento de la nacionalidad y por las políticas de inmigración existentes. Así, encontramos países con larga tradición receptora de inmigrantes como Francia, Alemania o Austria que consideran que integrar es asimilar a los inmigrantes a su cultura, mientras que otros se muestran más tolerantes con la diversidad (Reino Unido o Irlanda); o incluso promueven o han promovido el multiculturalismo (Suecia, Países Bajos, Australia). La dificultad que antes señalamos se hace aquí obvia, porque todos consideran que su enfoque conduce a la integración.

- Políticas de prestaciones sociales. En este sentido puede establecerse una clasificación dicotómica entre aquellos países que cuentan con un avanzado sistema de protección social (Suecia, Finlandia, Dinamarca, Países Bajos) o aquellos en los que el porcentaje del PIB destinado a este tipo de coberturas es menor (España, Italia, Estados Unidos ${ }^{7}$ ). Este hecho tiene consecuencias sobre el grado de cobertura de necesidades básicas que encontrarán los inmigrantes.

7 Aunque el alcance de las prestaciones sociales es mucho mayor en el entorno europeo que en el estadounidense, debe también reseñarse que, entre el Norte y el Sur de Europa, existe una gran diferencia en el monto de los recursos destinados a políticas de bienestar. 
- Actitudes acerca de la participación de los individuos en la sociedad. Existen diferentes modelos de aproximación a la participación de los individuos en la toma de decisiones de la sociedad. En aquellos países que presentan un mayor grado de desarrollo del tercer sector (Canadá, Estados Unidos, Países Bajos), las asociaciones de inmigrantes pueden llegar a constituir verdaderos lobbies. En otros lugares (España, Italia) el proceso de toma de decisiones viene bastante más centralizado por el Estado ${ }^{8}$, mientras que el tercer sector quedaría como una categoría subsidiaria encargada de prestar aquellos servicios no contemplados por el sector público.

Una séptima cuestión tiene que ver con si la integración se apoya en razones éticas o se deriva hacia la política. Si procurar la integración de los inmigrantes es tratar de que formen un cierto todo con la sociedad de acogida, evitando el mantenerlos en alguna forma de apartheid práctico, entonces la fundamentación ética de la necesidad de integrar a los inmigrantes es inmediatamente evidente. Y de hecho esta fundamentación ética, refrendada por la condena de la discriminación en los artículos 2 y 7 de la Declaración de los Derechos Humanos, es la que constantemente anima los empeños de las ONG pro-inmigrantes y las reivindicaciones de estos últimos.

Pero no deja de tener ciertos inconvenientes el concentrarse mucho en las perspectivas éticas al querer promover la integración. Y no sólo por la clase de motivaciones a que entonces se apela, sino también por la vaguedad de las consecuencias que desde esa perspectiva pueden sacarse en orden a cualesquiera realizaciones prácticas.

La toma de conciencia de la fundamentación política de la integración sería útil, no sólo para conseguir una mayor movilización ciudadana; también en orden a concretar lo que supone para el ciudadano y para el Estado el asumir o defender la integración. Porque si ésta aparece como una especie de absoluto cuando se presenta como obligación ética, sin explicitar sus costos y ventajas materiales o el modelo de convivencia y de Estado que se desea, todos estos aspectos deben ser inevitablemente tratados cuando se presenta la integración como opción política.

Pese a las siete precauciones o limitaciones enunciadas (y otras que se podrían añadir), integración es el mejor término que tenemos, hasta la fe-

8 En el caso de España al triple nivel de la administración pública: ámbito nacional, autonómico y local. 
cha, para referirnos tanto al proceso (deseable) que los inmigrantes, como nuevos colectivos, realizan a lo largo del tiempo para adquirir la condición de ciudadanos de pleno derecho, como al conjunto de políticas que propicien la incorporación positiva de inmigrantes y autóctonos en una sociedad multicultural.

\section{Cuatro dimensiones de la integración}

Este concepto de integración puede estructurarse a través de cuatro dimensiones: integración estructural, integración cognitivo-cultural, integración social y formación de la identidad ${ }^{12}$.

- La dimensión estructural (o aspectos normativos de la integración) dibuja las condiciones que determinan la participación del individuo en las instituciones de las sociedades avanzadas de nuestro tiempo, según el principio de igualdad de oportunidades. Incluye las siguientes variables: situación legal (ciudadanía, residencia), estatus dentro de los sistemas de educación y cualificación, posición en el mercado laboral, fuentes de recursos económicos, acceso a la vivienda y acceso a los sistemas de bienestar ${ }^{13}$.

- La dimensión cognitivo-cultural hace referencia al proceso que engloba el aprendizaje de habilidades cognitivas y el manejo de la cultura (especialmente el idioma) del país de destino. Esta dimensión implica la internalización de valores, normas y actitudes y puede llevar aparejado un cambio en las creencias y modos de proceder del individuo, en sus expectativas acerca de su desarrollo futuro -social o laboral-, en sus

9 Cf. F. Heckmann (1999), "Integration Policies in Europe: National Difference or Convergence?", Proyecto EFFNATIS; R. APARICIO y A. Tornos (2000), "Immigration and Integration Policy: Towards an Analysis of Spanish Integration Policy for Immigrants and CIMs"”, Proyecto EFFNATIS; C. GiMÉNEZ (1992), "Perspectivas, implicaciones y recomendaciones en torno a la inmigración en Madrid", Alfoz 91/92, pp. 103-113.

10 Este enfoque predomina en los gobiernos de los países europeos. En ellos se supone que está bien integrado el individuo a quien se le reconocen sus derechos y hace uso de ellos activamente en la convivencia, todo ello dentro de un marco jurídico adecuado. Ese sería el objetivo de las políticas de integración y por eso, para valorar el nivel de la integración, lo que se explora es el ejercicio de estas relaciones jurídicamente regladas por parte de los inmigrados y la calidad del marco jurídico. Los conflictos que las políticas de integración deben solucionar son los derivados de las deficiencias de las leyes y de su puesta en práctica. 
creencias personales e incluso religiosas. Se trata de un proceso interactivo en el cual se producen cambios tanto en los grupos de inmigrantes como en la sociedad de destino, aunque, dada la asimetría de poder existente entre ambos grupos, tales cambios revisten una importancia mucho mayor entre los inmigrantes. Las variables que determinan la dimensión cognitivo-cultural son el conocimiento del idioma y de la cultura del país de inmigración, los valores políticos, los valores culturales (familiares, roles, de género), así como las creencias religiosas y estilos de vida.

- La dimensión social de la integración implica las relaciones sociales y grupales del individuo, el desarrollo de las mismas dentro o fuera de su comunidad étnica y la facilitación de cauces de participación en la sociedad receptora de los colectivos de inmigrantes. Factores determinantes para la definición de esta dimensión serían la extensión e identidad de las relaciones familiares, el contacto con los miembros de la misma comunidad, los contactos con el vecindario, las relaciones de amistad, noviazgo y pertenencia o vinculación a asociaciones voluntarias (ONG, clubes, parroquias, etc.).

- La dimensión de identidad abarca los aspectos subjetivos de pertenencia e identificación personal con la comunidad étnica o nacional. Por descontado, existen diversos matices intermedios entre la identificación absoluta y la desidentificación total, bien con la cultura de origen, bien con la cultura de destino. Las variables que definen esta dimensión son la percepción subjetiva de pertenencia (nacional o étnica); las actitudes de los inmigrantes hacia la sociedad de acogida y de ésta hacia aquéllos; la clase y grado de identificación con la misma; y la orientación de la sociedad de acogida hacia las relaciones interculturales.

Como los mandamientos, estas cuatro dimensiones se resumen en dos: la socioeconómica y el antropológicocultural. La primera, que estaría ligada a las dimensiones estructural y social, implica que la incorporación del inmigrante al nuevo contexto social se haga en condiciones tales que le permitan llevar una vida digna (esto es, no suponga un factor de pobreza o exclusión social). Y la segunda, vinculada a las dimensiones cognitivo-cultural e identitaria, consiste en que el inmigrante aúne y haga compatibles los dos contextos culturales: el de partida (como cultura propia) y el de destino (o cultura extraña que debe aprender y respetar). Se conformaría entonces el itinerario de migración, asentamiento e integración como un proceso de nueva cultura, una nueva sociedad. 
Estas dos claves son fundamentales para comprender crisis que se dan en nuestras sociedades de inmigración como la de las revueltas juveniles en los barrios de los suburbios de las ciudades francesas del otoño de 2005. Señalar el problema de la pobreza o de la exclusión social no tiene que ocultar la importancia capital que poseen las cuestiones del reconocimiento y la identidad. Siendo el análisis de las condiciones sociales que están detrás de las revueltas de todo punto imprescindible, no es incompatible con el análisis ético-antropológico. Es cierto que la lectura ética-antropológica, cuando minimiza la importancia de lo socioeconómico, se acerca peligrosamente al enfoque etnicista. Ahora bien, creo que sin este segundo horizonte de análisis antropológico queda pobre e incompleto el socio-económico. El quid está en no dejar de lado ni la dimensión socioeconómica ni la antropológicocultural ${ }^{11}$.

\section{El rumbo de la integración de la inmigración en la Unión Europea}

En el Tratado de Maastricht (1992) el asilo y la inmigración formaron parte del "Tercer Pilar", o sea, de los asuntos de Justicia e Interior que, aunque apelan a la cooperación intergubernamental, siguen siendo competencia de las distintas naciones. La cooperación intergubernamental se lleva a efecto mediante reuniones de los ministros responsables en cada país de las cuestiones migratorias.

En el Tratado de Amsterdam (1997) se da un paso ulterior en la "comunitarización" de las políticas migratorias. Se pasan del Tercer Pilar (asuntos de Justicia e Interior propios de cada país, para los que se demanda cooperación inter-gubernamental), al Primer Pilar (asuntos que se sustraen a la competencia de los gobiernos, para decidirlos a nivel de la Comisión Europea). Pero este cambio no fue automático sino progresivo: el año 1999 entrada en vigor el Tratado de Ámsterdam. A partir de esa fecha, se daban cinco años para que la Comisión Europea asumiese sus competencias en materia de inmigración, pero exigiéndose todavía el voto unánime de todos los Estados miembros para que lo que se acuerde adquiera fuerza de ley; a partir de entonces siendo suficiente la mayoría cualificada en los Consejos Europeos de ministros como condición para que las disposiciones en esa materia se hagan obligatorias para todos los Estados.

11 He tratado extensamente ese tema en: J. L. MartínEz (2006), "Revueltas juveniles en Francia: una interpretación", Razón y Fe (marzo), pp. 209-228. 
En la situación actual, hay en la Comisión Europea un comisario que tiene entre sus competencias los temas de inmigración y ya se han publicado varias propuestas de la misma Comisión (entre otras, una sobre inmigración y otra sobre asilo) que tratan de sentar las bases sobre las que se desarrollará la normativa comunitaria sobre ambas temáticas y la dirección hacia la que se orientarán una política europea común sobre migraciones. Pero estamos aún lejos de una política verdaderamente común sobre inmigración y seguimos en el empeño de "coordinar las políticas nacionales". En España nos hemos hecho muy conscientes de tales dificultades a raíz de la búsqueda de acuerdos migratorios para afrontar la llegada de miles de subsaharianos a las Islas Canarias.

Lo que vemos echando la vista atrás es que muy pronto empezaron a aparecer dificultades para la puesta en práctica de esta autoridad de la Comisión, que se agudizaron con las crisis sufridas por varios Estados miembros. En varios de ellos comenzaron a manifestarse inquietudes ante el carácter excesivamente generalista de las políticas migratorias emanadas de la Comisión, poco atentas a las circunstancias particulares de unos países y otros. Basta recordar las protestas que se produjeron en Francia con ocasión del ascenso de Le Pen, en Austria con Hayder, o incluso en Holanda (uno de los países más liberales hacia el multiculturalismo) a raíz de los asesinatos del político Pim Fortuyn y del cineasta Theo van Gogh. Todo esto, por otra parte, dio mayor audiencia a los países que desde tiempo atrás se mostraban más reticentes a la apertura migratoria (casos de Dinamarca y Austria, particularmente).

El Programa de la Haya (2004) se hizo eco de estas nuevas preocupaciones. En él se retoma la temática de la integración de los inmigrantes con mayor detenimiento que en toda la época anterior ${ }^{12}$ y se propone la necesidad de una nueva formulación de los principios básicos comunes para la integración de los inmigrantes. En esta línea hay que situar la definición de unos principios básicos comunes, aprobada en el Consejo Europeo tenido en Bruselas el 4 y 5 de noviembre de 2004, que arranca de un concepto de la integración como proceso bi-direccional (a two way process), en el cual no sólo ha de atenderse a lo que los Estados de la Unión deberían aportar a los inmigrantes, sino también a lo que los inmigrantes mismos necesitarían poner de su parte para la integración. En particular el respeto de los valores europeos, el conocimiento básico del lenguaje, historia e instituciones de

12 Documento en http://www.statewatch.org/news/2004/nov/hague-programme-final.pdf 
los países de acogida y la conveniente interacción con los miembros de la sociedad nativa ${ }^{13}$.

A través de estos desarrollos se ve que sigue trabajándose en delinear una política europea de integración, pero que la iniciativa ha pasado de la Comisión a las sucesivas presidencias semestrales, dándose entrada con ello a mayor pluralismo y a un estilo de sensibilidad más cercano a las inquietudes concretas de los países miembros, menos dictado por planteamientos generales.

En esa misma cumbre de Bruselas se aprobó también un nuevo decálogo de integración de los inmigrantes, sentando las bases de un nuevo rumbo en el Unión Europea. Helo aquí:

- Favorecimiento de acciones efectivas contra la discriminación de los empleadores.

- Ofrecer oportunidades de formación a los inmigrantes.

- Reconocimiento de las cualificaciones obtenidas en otros países.

- Respeto a loa valores básicos de la UE.

- Programas de actuación para que los inmigrantes conozcan la lengua, la historia y las instituciones del país, sin impedirles el mantenimiento de su idioma y cultura.

- Apertura de las instituciones públicas y los servicios de alojamiento y educación.

- Transparencia a la restricción de los derechos de los no nacionales.

- Salvaguardia del derecho a la libertad religiosa, a no ser que su práctica entre en conflicto con otros derechos inviolables.

- Fomento de la participación en los procesos democráticos.

Este nuevo decálogo está en sintonía con las cuestiones a que la población europea, desde los años ochenta, se ha vuelto hipersensible: el pleno empleo, la paz social, el orden público y la seguridad ciudadana. Por eso las políticas migratorias que predominan en los países europeos son prácticamente las mismas en todos: prioridad de los nativos sobre los inmigrados en el acceso

13 http://europa.eu.int/comm/justice_home/funding/doc/council_conclusions_common_basic_principles. 
al trabajo, vinculación del derecho a inmigrar a los permisos de trabajo, lucha contra la inmigración ilegal y contra los racismos y xenofobias, extensión de las prestaciones del Estado de bienestar a los inmigrantes legales.

A partir de estas cuestiones centrales comienzan las diferencias, las cuales al ser subrayadas por los medios de comunicación, por los partidos políticos y por sectores sociales particulares (ONG, juristas...), pasan muchas veces a ser más importantes que lo común. Estamos ante un típico ejemplo en que la insistencia en lo diferente oculta lo que es común.

\section{Principales modelos de referencia atendiendo a las culturas políticas de los países}

Nos encontramos, por tanto, con las líneas básicas de un aparente consenso sobre la integración de las sociedades europeas de inmigración y, al mismo tiempo, con el hecho de la imposibilidad práctica de que exista un único modelo de integración: y es que el propio concepto implica, como ya se ha indicado, una interacción con el entorno, y dicho entorno varía en el espacio, dando así lugar a diferentes percepciones de la integración y, por ende, a diferentes modelos.

La integración de los inmigrantes, o sea el proceso a través del cual llegan ellos a constituir un "todo" único con la población de los países de destino, es un proceso extraordinariamente complejo y en cierto modo muy relativo -relativo en el sentido de que la integración no podrá menos de producirse con relación a la manera de ser de la sociedad a que llegan.

Cuando un francés, por ejemplo, piensa en lo que significa integrarse, parte de la idea preexistente en la sociedad francesa acerca de lo que es integrarse. Igual pasa con un inglés. Pero cuando franceses, ingleses y otros europeos quisieron avanzar hacia políticas de inmigración comunes, se dieron cuenta de que unos y otros estaban refiriéndose a propósitos distintos cuando hablaban de promover la integración.

Para clarificar estas diferencias expondré brevemente en este apartado los contornos de los dos principales modelos de integración político-cultural en Europa: el francés y el británico (sobre el alemán del Gastarbeiter ya he dado más arriba una pincelada). En el apartado siguiente haré lo propio con los modelos de integración política o modelos de ciudadanía (modelos liberal libertario y liberal social, modelo comunitarista, modelo multicultural, modelo republicano, modelo comunicativo), analizando sus posibilidades en 
relación a una cuestión controvertida como la del uso de símbolos religiosos en los ámbitos públicos.

\subsection{El modelo francés: "asimilacionismo republicano"}

Suele decirse que en Francia la integración de los ciudadanos se realiza por identificación con el ideal republicano de una ciudadanía idéntica para todos, el cual ideal subraya que todos los franceses son absolutamente iguales en el espacio público, sin que las normales diferencias que pueden distinguir a unos de otros puedan importar fuera de la vida privada.

Este ideal se llama republicano contraponiéndolo a lo que era Francia antes de la Revolución: el ideal republicano afirma sobre todo la igualdad. A él se habría llegado a través de costosos esfuerzos y negociaciones por marcar los límites entre el espacio público (un espacio de igualdad) y el espacio privado, en que se consideraba normal que unas personas fueran diferentes de otras.

Por ejemplo: no fue fácil llevar a la práctica la idea de que la igualdad debía relegar a la vida privada todo lo que fuera práctica religiosa o anti-religiosa (el estilo del Estado laico francés, que es algo más que Estado aconfesional, como aparece comparando la modalidad francesa de éste con la que predomina en Estados Unidos). Tampoco fue fácil relegar del todo a la esfera privada lo distintivo de las distintas regiones francesas (Bretaña, Normandía...). Desde España sabemos bastante de las diferencias que se pueden demandar desde los diversos territorios.

Por lo que toca a los inmigrantes la consecuencia más inmediata es que si uno de ellos quería integrarse bien en Francia se suponía que adoptaría esa idea republicana de lo francés y querría igualarse con los franceses - al precio de esconder en su intimidad el sentimiento de pertenecer a otro país y a otras costumbres (en el sentido emocionalmente fuerte que dan los psicólogos angloamericanos a este sentimiento de pertenencia o sense of belonging), con la consiguiente renuncia a invocar en público esa su pertenencia diferente. $\mathrm{Si}$ las religiones son para la sacristía, las diferencias nativas de costumbres y cultura tenían que esconderse en la cocina (expresión culinaria) o dejarse ver sólo como folclore.

Esto tiene consecuencias importantes. Por ejemplo: según la Declaración de los Derechos Humanos toda persona tiene libertad para elegir y practicar su religión. Pero en Francia una mujer musulmana no puede ir a un centro 
de enseñanza con el velo prescrito por sus costumbres, porque eso se entendería como actitud de provocación contra el ideal republicano de la privacidad de la religión.

Pero todo esto son problemas que han aparecido después. En realidad no se pensaba en ello cuando tomó forma el modelo de integración de los inmigrantes que suele llamarse francés. Cuando ese modelo nace, nace desde la persuasión de que la buena convivencia en la sociedad francesa se atiene al ideal republicano y que a los inmigrantes, si les vale la pena vivir en Francia, el atenerse a ese ideal les abrirá todas las puertas.

Vistas las cosas desde la situación actual no deja de parecer que ese modelo francés lleva directamente al asimilacionismo, es decir, a concebir el proceso de integración de los inmigrantes como una marcha hacia la plena asimilación de los usos y prácticas del país de acogida, con abandono de sus propias raíces. Es desde este punto de vista desde donde actualmente suele criticarse el modelo francés.

\subsection{El modelo británico: "multiculturalismo pluralista"}

La experiencia histórica de la Inglaterra de los siglos XIX y XX ha marcado a la idea espontánea que tienen los ingleses de lo que es pertenecer a su país no menos que lo que marcó a los franceses su experiencia histórica. Pero, por cierto, en un sentido contrario al de Francia. Mientras en Francia se forja durante ese tiempo el ideal republicano unificador de todos los franceses y se trabaja por llevarlo a la práctica y por defenderlo, en el Reino Unido se está asimilando en profundidad lo que significa pertenecer a un imperio pluralista, en el cual las personas y grupos no tienen por qué uniformarse. Francia hacía su unidad intentando borrar las diferencias, Inglaterra la hacía incorporando las diferencias a su ser imperial y social.

Todavía no estamos en la Europa multicultural de hoy, pero en esta fase de la experiencia política inglesa dos aspectos son de interés para nuestra reflexión sobre las formas de vivirse la integración en el país. Primero, que a través de esa experiencia política las diferencias cívicas ya no pretenderán concebirse como cuestión privada y simple pluralismo de gustos, sino como formas de vida legítimamente distintas, compartidas cada una de ellas públicamente por unos u otros sectores de la población. Segundo, que en este pluralismo no sólo se reivindica la necesidad de tolerar a los diferentes: se reivindica además el derecho de los grupos diferentes a tener un lugar ins- 
titucionalmente reconocido en el orden político y a recibir apoyos públicos para no disgregarse.

Si en el trasfondo de la idea de pertenencia al Reino Unido tiene alguna vigencia esa manera de entenderse la convivencia cívica, entonces es lógico que al pensarse en la integración de los inmigrantes al país no se piense en uniformarles, se piense más bien en dar un sitio a sus colectivos. Y así un inmigrante, para integrarse en el Reino Unido, deberá mantenerse integrado en su minoría étnica, la cual a su vez deberá acertar a integrarse con las demás minorías y con la mayoría. Por eso en la literatura sociológica inglesa encontramos raras veces que se trate de problemas de integración de unos u otros inmigrantes (vistos como individuos). En vez de eso se trata de los problemas que puede ocasionar una u otra minoría, o sea, de las llamadas relaciones interétnicas.

¿En qué consiste pues el llamado modelo inglés de integración? En lo contrario del francés. Si este promueve la adopción por los inmigrantes de una ciudadanía francesa uniforme y única, el inglés se despreocupa de esto. Si en Francia es anticonstitucional la formación de minorías, en el Reino Unido se tiene por conveniente canalizar las políticas de integración a través de debates con minorías bien organizadas. Desde un punto de vista francés los ingleses integran a los inmigrantes como ciudadanos de segunda clase. Desde un punto de vista inglés las clases existen de todas formas, y también en Francia; pero si un inmigrante no puede asociarse públicamente con sus connacionales tendrá mayores dificultades para defender públicamente sus derechos.

El libro de Jeremy Paxman, Los ingleses, retrato de un pueblo, recoge unas palabras de Kaki Badawi, presidente del Consejo de los Imanes y de las Mezquitas del Reino Unido, en las que declara que "no hay mejor lugar en el mundo que el Reino Unido para ser musulmán”. Esta opinión tan positiva se basa en la flexibilidad y la tolerancia con que se acoge a los inmigrantes, a los que no se les exige ni saber inglés ni adherirse a los valores del país al que se incorporan. Pero detrás de esta superficie late una realidad no tan bonita: más del 80\% de musulmanes con salarios inferiores a la media nacional, con una tasa de desempleo tres veces superior a los nacionales o europeos, con altísimas cotas de fracaso escolar, por citar tres asuntos relevantes.

Los atentados del 7-J en el Metro de Londres han venido a hacer visibles algunas cosas del modelo británico de afirmación múltiple y diferenciada de las culturas, que no parecen funcionar adecuadamente. 
En fechas muy recientes hemos visto cómo destacadas personalidades de la vida política británica empiezan a sugerir cosas que, como mínimo, apuntan hacia un replanteamiento del modelo inglés. En este sentido, son interesantes las declaraciones del líder de la Cámara de los Comunes y ex ministro, Jack Straw ${ }^{14}$, en las que afirmó que el velo islámico que llevan las mujeres podría dificultar las relaciones entre las distintas comunidades, ya que supone "un ejemplo visible de separación y diferencia". Acuerdos o desacuerdos aparte, lo que parece bastante claro es que este argumento no puede ocultar su afinidad con el republicanismo asimilacionista.

\section{3. ¿Un modelo español?}

Siempre que uno habla de los modelos de nuestros vecinos, alguien avispado pregunta si hay un modelo español. Y la respuesta es un contundente: "no lo hay"; o un más matizado: "algún rasgo propio sí hay, pero un modelo como tal no". Sea un no rotundo o un no con matices, la pregunta acompañante es más importante: ¿deberíamos hacer un esfuerzo por que lo hubiese o es suficiente con "copiar" de otros?

De entrada, es natural que no haya un modelo español, al menos algo que se pueda presentar con la nitidez de otros modelos, puesto que España no es un país tradicionalmente receptor de inmigrantes, en el cual haya tenido tiempo de tomar forma una manera propia y coherente de representarse la integración de éstos. Por lo demás ésta, cuando ha llegado a plantearse en las esferas políticas, ha tendido a concebirse con arreglo a las orientaciones predominantes sobre todo en Francia.

Además, a falta de la experiencia histórica, el tipo de enfoque al que fácilmente se puede recurrir es el que comúnmente se llama legal o formal. Es decir, el enfoque que atiende casi exclusivamente a los textos jurídicos que tratan de dichas políticas, examinando sus contenidos, su significado y oportunidad, las condiciones en que operan, las alternativas más idóneas que podrían elegirse. Lo que pasa es que en nuestro caso tampoco el itinerario legal ha sido muy brillante: el farragoso itinerario legislativo con dos leyes orgánicas en un mismo año -el 2000- y otra con menos de tres años de diferenta -el 2003-, salpicado de regularizaciones extraordinarias (la úl-

14 Straw es parlamentario del Partido Laborista por la circunscripción de Blackburn, donde una cuarta parte de sus ciudadanos profesa la fe musulmana. 
tima de las cuales, en 2005, regularizó a 556.000 inmigrantes), es prueba de la confusa o difusa dirección que ha tenido la política migratoria española. No por farragoso, sino por ser materia de buenos y abundantes estudios ${ }^{15}$ lo omito aquí.

Para que se pueda hablar de modelo español de integración social de la inmigración no basta con el enfoque legal, hace falta otros enfoques como los que prioritariamente se fijan en la distribución de los poderes que actúan a través de las políticas tendentes a la integración social o en el estilo de cultura política-pública a que ellas responden. Algo se podrá hacer en ese sentido porque también en España hay unas experiencias históricas de lo que es estar integrado en el país, y por cierto nada parecidas a las que impregnan el sentimiento de pertenencia a su tierra que tienen los franceses o los ingleses.

Aparte de otras consideraciones, el modelo francés ya sería inaplicable en España por el pluralismo cultural oficialmente reconocido entre nosotros con el reconocimiento de las autonomías. Y también sería muy difícil que funcionara el modelo inglés, por lo menos en cuanto a la forma en él prevista de canalizar las demandas de los inmigrantes y las inversiones dirigidas satisfacer dichas demandas, tocantes a su integración, a través de organizaciones e instituciones creadas por ellos mismos, reconociendo la interlocución política de las minorías étnicas.

Con lo dicho no hemos avanzado gran cosa, pero sí hasta el punto de decir que lo más inteligente será poner las condiciones para crear un modelo español de integración para dar unidad y sentido a las distintas medidas sociales que habrá que ir tomando para una sociedad con millones de inmigrantes. Ni nuestra cultura política-pública española es la francesa o la inglesa, ni conviene olvidar que esos modelos están siendo sometidos a revisión en sus respectivas culturas públicas. Apuntarse a algo que otros ya han probado $y$, tras experimentarlo ven que necesitan reenfocar, puede ser explicable cuando uno está perdido y sin saber por dónde tirar, pero ciertamente no parece la estrategia más sabia.

15 Cito un libro muy reciente (resultado de un conjunto de estudios de varios especialistas) que ha visto la luz en el Instituto Universitario de Estudios sobre Migraciones de la Universidad P. Comillas: J. M. Ruiz de Huidobro (ed.) (2006), La regulación legal de la inmigración y la extranjería, Madrid. 


\section{Modelos de ciudadanía e integración}

Puede ser útil para seguir pensando la integración esbozar otra tipología que utiliza los modelos, pero ahora de los modelos de ciudadanía. Lo haré ofreciendo una somera revisión teórica de cada uno de los más importantes modelos en relación a la discutida cuestión del uso de los símbolos religiosos en los espacios públicos que dependen del Estado. Es célebre en este sentido la Ley francesa de prohibición de símbolos religiosos (popularmente, ley del velo) en las escuelas, que aprobó el Parlamento galo a partir del Informe Stasi. Últimamente, como más arriba he tenido la oportunidad de decir, algunas voces de destacados políticos británicos también han comenzado a remover el asunto señalando las dificultades que usar tales prendas tiene para la integración de las mujeres.

7.1. Breve recorrido por los modelos y el uso de símbolos religiosos en el espacio público

El modelo liberal de ciudadanía proclama la neutralidad estatal ante diferentes concepciones morales y religiosas. El pluralismo es entendido como libertad de elección. El Estado debe asegurar las condiciones institucionales para que individuos y comunidades que poseen credos diferentes puedan convivir en paz. El liberalismo libertario hace suya la máxima que reza "vive y deja vivir". Las únicas obligaciones cívicas del ciudadano liberal se limitan a respetar los derechos ajenos y a cumplir con el orden social que garantiza sus propios derechos e intereses. Así en la sociedad liberal los individuos se asocian libre y voluntariamente para perseguir sus propios intereses con distintos fines, ya sean culturales, deportivos, económicos o religiosos. El uso de los símbolos religiosos debería ser únicamente decisión de los individuos y su libertad. Por lo tanto, en un Estado neutral donde el hombre tiene garantizada la libertad de conciencia y de pensamiento, la libertad de palabra y de reunión y, sobre todo, la libertad religiosa y moral, el uso del velo en la vida pública se supone, en principio, garantizado.

En el liberalismo político de Rawls ${ }^{16}$, la razón pública es el ámbito de "las esencias constitucionales y asuntos de justicia básica”. La concepción pública de justicia de Rawls es independiente de doctrinas religiosas filosóficas o morales. En este sentido, las instituciones políticas están concebidas para satisfacer la justicia y la estabilidad política; y ambos principios se conci-

16 J. RaWls (1996), El liberalismo político, Barcelona. 
ben partiendo de la base de que estamos en una sociedad marcada por un pluralismo razonable. El Estado de Rawls garantiza la capacidad de profesar una creencia a través de un orden político definido por los derechos y libertades básicas. Toda idea religiosa es aceptable dentro del respeto a los principios de justicia política. En virtud de la libertad de cultos cada uno elige libremente su creencia. Y es que los derechos de los individuos sirven para proteger derechos de asociaciones en un marco regido por los principios de la justicia política.

Sin embargo, Rawls opta por la no relevancia, desde un punto de vista público, de las identidades religiosas. No trata directamente la cuestión del velo musulmán, pero sí la de la oración en la escuela abierta al pluralismo de religiones. A su juicio la oración debe estar fuera de ella, pero de ahí no se debe deducir que el liberalismo político sea una concepción política individualista, puesto que su finalidad es la protección de los diversos intereses en libertad, tanto individuales como asociativos; ni se ha de concluir que la separación entre la Iglesia y el Estado tenga como objetivo primario la protección de la cultura secular, por supuesto protege la cultura pero no más que a todas las religiones. Los símbolos religiosos deben quedar fuera de la esfera pública.

En el modelo rawlsiano, el Estado no ha de prohibir el uso del velo u otros símbolos religiosos en el ámbito no público del "trasfondo cultural de la sociedad", esto es, en el espacio de las razones no públicas, donde los grupos se organizan de acuerdo a propias elecciones valorativas de índole religiosa, moral o filosófica, y los individuos eligen libremente a qué grupo quiere pertenecer. Pero sí lo debe hacer, si se estima que tales símbolos irrumpen en el espacio de la razón pública, que es de todos, y donde ha de regir la neutralidad, relegándose lo que pueda generar división, exclusión y desencuentro. En el espacio público, el de la cultura pública, rigen los acuerdos y consensos de la cultura liberal, los valores y las tradiciones políticas e institucionales compartidas y que garantizan los espacios de libertades individuales. Por tanto, en el espacio público no se atiende, ni se reconocen, de principio, las configuraciones religiosas, éticas o culturales particulares y específicas, ya que es un espacio culturalmente neutral. Ahí los individuos son ciudadanos y no creyentes. El pañuelo es constitutivo de la identidad no pública, pero no de la identidad pública, cuya cultura pública se enraíza en el sentido común compartido y en las tradiciones históricas del liberalismo: por eso su identidad cultural, de la que es una representación debe quedar fuera de la esfera pública. 
Frente al liberalismo, el Estado que proclama el comunitarismo es activista. Debe y puede alentar a las personas para que se adecuen a la forma de vida de la comunidad. Para los comunitaristas, la persona pertenece a una comunidad política no sólo por vínculos jurídicos, sino también por vínculos identitarios. Taylor señala que la identidad de la comunidad debe ser reconocida, tal y como es la del individuo, y aboga por una política de reconocimiento de la identidad ${ }^{17}$. El uso del velo en el espacio público visto a través del modelo comunitarista puede recibir dos soluciones, dependiendo del Estado en el que nos encontremos. Por un lado, si nos encontrásemos en un Estado musulmán, el uso del velo en espacios públicos no choca con reproche alguno, pues es un símbolo religioso que refuerza la identidad de la persona que lo lleva y le da sentido de pertenencia a un grupo. Por otro, la estructura de las sociedades modernas se está viendo crecientemente afectada por el fenómeno de la multiculturalidad, algo que presenta nuevos conflictos y cuestiones en la medida en que las minorías étnicas y nacionales piden que se reconozca y se apoye su identidad cultural.

¿Qué pasa, pues, cuándo el uso del velo se da en una sociedad donde la identidad mayoritaria no es la musulmana? Con otras palabras, el inmigrante musulmán que llega a un Estado europeo, laico o aconfesional, de tradición cristiana, para tener garantizados unos bienes, ¿tendrá que abandonar el uso del velo en el espacio público, así como otras costumbres, e integrarse en una nueva identidad comunitaria? El velo sólo tendría sentido en el espacio público en el contexto de una comunidad moral donde ese signo tenga relevancia. Pero no tendría sitio en un contexto cultural donde sea minoritario su uso y donde lo que prevalezca sea la afinidad étnica-cultural y nacional como principio sustentador de la participación política. Porque, entonces, el símbolo diferente, aparece ya como disolvente de la cohesión de la comunidad $\mathrm{y}$, por tanto, como amenaza de la comunidad moral que genera identidad y pertenencia, y sobre la que en última instancia descansa la comunidad política y las políticas de justicia y solidaridad. De hecho, el modelo comunitarista es el que más claramente ha defendido una política de admisión de inmigrantes restrictiva justificada en la salvaguarda de la identidad comunitaria y la defensa la libertad así como el bienestar de la comunidad ${ }^{18}$.

17 Ch. TAYLor (1993), "La política del reconocimiento", en: El multiculturalismo y la política del reconocimiento, México, pp. 43-107.

18 Tal como ha hecho M. WALzER en el capítulo $2^{\circ}$ de Las esferas de la justicia, de 1983 (traducción castellana de 1993). 
Según Kymlicka y su modelo de ciudadanía multicultural ${ }^{19}$, no se puede aplicar una fórmula única a todos los grupos, ya que las aspiraciones y las necesidades de los inmigrantes son muy diferentes. Se dice de Kymlicka que está a caballo de aquellos que exageran el derecho a su cultura y no respetan los derechos de los demás y de los que tienen fobias a las diferencias. Aboga por la integración de las minorías culturales en sociedades con una cultura mayoritariamente dominante, pero también por que el Estado reconozca una identidad política a los grupos nacionales o con una etnicidad específica (musulmanes). Por una parte, diría que la mujer musulmana que apuesta por la integración se olvidará del velo; pero, por otro lado, afirmaría que, si lo que dota de sentido a la libertad individual es la participación en culturas concretas y el Estado reconoce los derechos colectivos de la diversidad etnocultural, la mujer no tiene por qué encontrar reproches si utiliza el velo en espacios públicos. Si se tiene en cuenta la existencia de un grupo minoritario como el musulmán dentro de una sociedad laica, la mujer musulmana podría vestir con velo en la vía pública en tanto en cuanto es un símbolo de la identidad del grupo minoritario al que pertenece.

Lo tendrá más difícil la mujer musulmana que quiera llevar velo y aterrice en un Estado laico con un modelo republicano de ciudadanía ${ }^{20}$, como sucede en el caso concreto de Francia. La concepción republicana define al ciudadano como alguien que participa activamente en la configuración de la sociedad a través del debate y de la elaboración de las decisiones públicas. El ciudadano dispone de un conjunto de derechos y debe comprometerse con la comunidad política a través de la participación en la vida pública para buscar consenso sobre los asuntos que atañen al bien común. En la nación, el ciudadano encuentra su afinidad étnico-cultural. Esto implica que el inmigrante deberá optar por la asimilación si quiere que se le reconozca como ciudadano y relegar al plano privado sus creencias religiosas. La ciudadanía supone amor a la patria e identificación con sus símbolos y valores fundamentales; una patria vista como ordenamiento político y cultural, cuyos miembros comparten leyes, valores y costumbres y se protegen de la contaminación cultural. Por lo tanto, será muy probable que el uso del velo en espacios públicos sea vetado, pese a que entre las prácticas políticas que implica la ciudadanía republicana está que para que un individuo sea responsable de su vida tiene que encontrarse en condiciones de elegir.

19 W. Kymlicka (1996), Ciudadanía multicultural, Barcelona.

20 P. Peтtit (1997), Republicanismo, una teoría sobre la libertad y el gobierno, Barcelona.

\section{RFS}


Una salida distinta vendría si se aplicase el modelo comunicativo de ciudadanía de Habermas ${ }^{21}$. En él, los inmigrantes no tienen por qué adherirse a las tradiciones culturales específicas de la sociedad de acogida ni asimilarse a una identidad nacional definida por una historia que no es la suya. La mujer musulmana no tiene por qué renunciar a llevar el velo. Eso sí, existe un cuerpo de principios como los derechos humanos, el imperio de la ley y la democracia, a los que el inmigrante debe comprometerse para poder ser aceptados en la comunidad política.

Habermas distingue entre integración ética e integración política ${ }^{22}$. Cree que las políticas de admisión de inmigrantes pueden imponer condiciones para salvaguardar la identidad o integración a la cultura política de la comunidad, pero no a una determinada forma de vida cultural. En consecuencia, no podría vetar el uso del velo, por ejemplo, a las mujeres musulmanas, en tanto que expresión de su integridad cultural religiosa y familiar; pero sí podría prohibirlo como símbolo de humillación femenina, en tanto que vulnera los derechos humanos, con tal que esto no sea decretado a partir del juicio de los particulares disgustados por ese tipo de prácticas supuestamente discriminatorias contra las mujeres. El asunto es más complejo y requiere de una sólida argumentación probatoria, porque la opinión de las mujeres implicadas no se puede ignorar sin más.

\subsection{Lo que podemos aprender de la cuestión del velo islámico}

El pluralismo cultural es un dato de la realidad. La cuestión es ver cómo se afronta, se construye y se trata ese dato de realidad multicultural. Y la primera condición es no excluir a la sociedad civil de la vida pública, aunque aceptando que no ha de confundirse con lo público del Estado.

De esta afirmación clave, extraigo algunas consecuencias para la cuestión del uso del velo en el espacio público, y en general, para la cuestión del multiculturalismo. Por un lado, la aceptación del pluralismo cultural, comunitario e individual, como eje articulador del espacio social no público, de la cultura ética de las democracias europeas, de los mundos de la vida. Por

21 J. HABERMAS (1999), La inclusión del otro, Barcelona.

22 "Denomino "éticas" a las cuestiones que se refieren a concepciones de la vida buena o de la vida no malograda...Entre las cuestiones éticas se inscribe gramaticalmente la referencia a la primera persona y con esto la referencia a la identidad de un individuo o de un grupo". Ibid., p. 203. 
otro, la aceptación de que las distintas tradiciones culturales presentes en el espacio social participen en la elaboración y revisión de la cultura política pública. Con todo, lo esencial será cómo se articulen ambos espacios, entre sí, y en cada uno de ellos.

El espacio de la sociedad civil es público y quedará configurado, no sólo como un espacio donde conviven las diferentes tradiciones culturales, con sus ideas de bien y de desarrollo personal, sino como el espacio generado por la razón comunicativa y deliberativa entre estas diversas tradiciones e ideas de bien, por el diálogo entre las distintas tradiciones en el mundo de la vida: serían los espacios intermedios del mestizaje intercultural. Esto requiere del diálogo intercultural, del cuestionamiento de lo propio, de la capacidad de escucha y conocimiento concreto, en primera persona, de los demás; requiere de la capacidad de salir de uno mismo para reconocer lo que de nosotros hay en el otro y las ideas que de bondad y belleza hay en otras tradiciones; requiere, por fin, del aprendizaje de distintos lenguajes culturales.

En este contexto el velo, en tanto que símbolo religioso que las mujeres libremente adoptan, obtendría reconocimiento como signo distintivo del pluralismo cultural. No podría obtener reconocimiento público como signo distintivo del espacio intercultural, de la identidad intercultural y de la cultura política, a no ser que sus connotaciones de símbolo de la instrumentalización de la mujer y de su subordinación al varón fueran desapareciendo paulatinamente de manera efectiva, hasta quedar sólo como signo del pluralismo cultural. En este sentido, la deliberación en el espacio intercultural, y la identidad intercultural, como identidad comunitaria estaría sometida al principio de dignidad y reconocimiento de las personas.

En fin, en la situación de pluralismo social que nos toca vivir, reivindicamos la pertinencia y relevancia pública de la propia identidad cultural, moral y religiosa (que no es para encerrar en los templos o en las sacristías, ni para configurar sólo las decisiones morales tomadas en el sagrario de la conciencia), desafiando al mito de la neutralidad, sin caer en el sectarismo de los lenguajes cerrados e incomprensibles para los otros: "Los argumentos dejan de ser civiles cuando su vocabulario se hace solipsista, y sus premisas son que mi pensamiento es sólo mío y no hay forma de compartirlo; cuando el diálogo se ha disuelto en monólogos. Cuando cosas como esas pasan, no es posible dialogar"23.

23 J. C. Murray (1960), We Hold These Truths, Kansas City, p. 14. 
Se trata de animar una comprensión de la integración intercultural e interreligiosa en línea con un pluralismo comprometido e inclusivo y una laicidad justa, que supone libertad religiosa, gracias a la cual el Estado abre el espacio social a las religiones para que sean factores en la construcción de la vida social y a los creyentes -que son participantes activos en la vida ciudadana- para que ofrezcan a la sociedad los bienes de naturaleza moral y temporal que han descubierto gracias a la luz de su fe religiosa.

\section{Hacia un modelo de integración plural, abierto e inclusivo}

\subsection{No iluso, sí valiente y creativo}

En la literatura sobre migraciones apenas se habla de otros modelos de integración fuera del francés o el inglés. Y ya más arriba se ha indicado por qué: por el menor peso del país cuyos estilos de integración, al tener un perfil propio, podrían dar nombre a un modelo; por ser estilos de integración que no se han llevado a la práctica consecuentemente, resultando por tanto inciertas sus consecuencias políticas y humanitarias; por basarse en ideas cuya puesta en práctica no roza cuestiones candentes, etc. Hoy es casi imprescindible conocerlos, pero no tanto ni principalmente para imitarlos, sino para aprender de lo que ha fracasado en esos modelos, y abrir nuevos caminos.

Pero además merecería considerarse -como le gusta decir al profesor Tornos- el modelo específico y distinto de integración que implícitamente orientó a fines del siglo XIX las políticas migratorias de los Estados con una clara conciencia de necesitar inmigrantes para su desarrollo económico y cultural. Por ejemplo, los Estados Unidos de entonces a donde afluyeron millones de europeos de muchas nacionalidades o la Argentina de entonces donde llegaron ingentes cantidades sobre todo de españoles e italianos.

Aunque acaso lo idealicemos, en aquellas sociedades estaba viva la conciencia de que necesitaban a los inmigrantes para no estancarse y degradarse y esto las llevaba a pensar transnacionalmente sus necesidades de mano de obra y el futuro de su desarrollo. Y por eso se alegraban con la llegada de los inmigrantes, aunque la primera inserción de éstos o sus roces ocasionales con los nativos pudieran crear importantes dificultades. En tales circunstancias la actitud con que abordaban las dificultades de la integración no podía ser sino mucho más constructiva y optimista, desde el convencimiento de que 
la inmigración era imprescindible para su progreso. En todo caso, el control de las fronteras no fue entonces la forma de responder.

Pues bien, en la tesitura en que estamos, por la evolución demográfica de los países de la Unión Europea, y concretamente la de España, ha llegado a un punto en que se ha vuelto del todo necesaria la llegada de inmigrantes para que la economía no se estanque y la convivencia, consecuentemente, no se degrade ${ }^{24}$. Como dato sintomático valga recordar que en 1991 había en España 3.325.541 jóvenes de entre 15 y 19 años, según datos del Ine; hoy, según el mismo Instituto, habría 2.655.734, o sea un 20,14 \% menos; y en los próximos años se prevé que las cifras van a seguir bajando. Esta pérdida de potencial de trabajo no se la puede permitir ningún país industrializado que quiera seguir creciendo.

\subsection{Integración política e integración ética}

Para elaborar este modelo creativo me parece muy útil -como marco de base- tener en cuenta la distinción que más arriba recordábamos como elemento de la ciudadanía comunicativa propuesta por Jürgen Habermas: entre una integración ética (cultural) de los distintos individuos y grupos, y una integración política en el marco común e igual para todos, marco que conforma los principios constitucionales, interpretados desde la experiencia histórica de la nación. La integración política respeta el pluralismo de comunidades en el nivel ético, que es subpolítico. La clave está en mantener constructiva y justamente la diferencia entre los dos niveles de integración.

Habermas recurrió al viejo concepto norteamericano de "patriotismo constitucional" (Verfassungspatriotismus) para explicar a los europeos occidentales por qué debían integrar sus naciones-Estado en una Unión Europea más amplia y cómo integrar en ella a las minorías inmigrantes. El patriotismo constitucional proporciona un principio rector atractivo para llevar a cabo esa segunda tarea. Los inmigrantes no tienen por qué adherirse a las tradiciones culturales específicas de la sociedad anfitriona ni asimilarse a una identidad nacional definida por una historia que no es la suya. Todo lo que se les pide (como condición sine qua non) es que suscriban aquellos valores políticos que son el fundamento de las constituciones democráticas. Existe un cuerpo de principios como los derechos humanos, el imperio

24 En estas estimaciones coinciden los estudios publicados por el Banco de España, el Bilbao-Vizcaya-Argentaria y el Santander Central Hispano. 
de la ley, la democracia, que son irrenunciables: con ellos los inmigrantes deben comprometerse para poder ser aceptados en la comunidad política. Son valores universales, que, aun cuando su codificación se haya realizado en las sociedades occidentales, su contenido es transcultural y pueden ser compartidos por todos los grupos y tradiciones. Aquí la cautela que hay que ponerle a Habermas es la de no "colar" dentro de las cuestiones de integración política otras de la identidad cultural prevalente, faltando al respeto a las culturas minoritarias. El caso de los símbolos religiosos aporta materia abundante para pensar.

En nuestro caso español, no hay duda de que los inmigrantes están entre nosotros. Probablemente no tantos como harían pensar las noticias alarmistas ni tan pocos para ignorar su presencia. Hay ya una España inmigrante. Y ello comporta ya, y va a comportar con mayor intensidad, cambios significativos en nuestra convivencia. Las generaciones venideras estarán marcadas por el mestizaje, se diversificarán usos, estilos de vida, prácticas religiosas, incluso el lenguaje que hablamos.

Pero esto más que un problema es una gran oportunidad llena de riqueza, aunque ciertamente no exenta de conflictos. Una gran suerte, sobre todo, si uno considera que en la sociedad de la globalización ninguna sociedad puede permanecer monolítica y cerrada sobre sí misma. Y las que lo intenten están llamadas al fracaso. Ahora bien, eso no significa que estemos en condiciones de derribar las fronteras o de dar por buena la entrada masiva de inmigrantes en situación irregular.

Si la nuestra ha de ser una sociedad más pluralista en mentalidades, culturas y religiones, también lo será en intereses. Su buena marcha dependerá de cómo acierte a estructurar democráticamente la resolución de las diferencias de intereses. En este sentido, establecer buenas vías para la integración de una sociedad con un importante componente inmigrante no es simplemente una cuestión ética y humanitaria, sino el germen de un futuro digno para nuestra sociedad.

\subsection{El valor ético de la sensibilización social y la opinión pública}

Los aspectos asociados a la sensibilización social y a la opinión pública son centrales para la actuación pública ante la inmigración y en consecuencia para la planificación de políticas de integración. Su importancia radica en el hecho de tener por destinatario a la población en su conjunto y, por lo 
tanto, dirigirse prioritariamente hacia la mayoría de la población autóctona. $\mathrm{Su}$ objetivo consiste en lograr que el conjunto de la población receptora adopte predominantemente una actitud realista, positiva, de aceptación, de tolerancia y de interés por el otro; pero también que la opinión pública y la opinión publicada se muestre realista, positiva y dé pruebas de tolerancia y aceptación frente a los que llegan de fuera.

No está de más tampoco recordar el célebre axioma de que "si los seres humanos definen una situación como real, acaban siendo reales sus consecuencias". Esto es, si la gente piensa que hay "demasiados" inmigrantes, el hecho es que sean pocos o muchos, la gente actuará en la práctica como si su número fuera efectivamente excesivo.

A pesar de la importancia de estos temas, hasta ahora no han recibido el tratamiento que requieren. Lo más que se les concede en un lugar secundario bajo el epígrafe de "sensibilización", lo que supone una perspectiva bastante reduccionista, puesto que las múltiples líneas de acción, en esta materia -posibles y necesarias- se limitan a un mero aleccionamiento propagandístico de la población autóctona. Además esta versión tan pobre de la tarea de sensibilización y conformación de la opinión pública se lleva a cabo de forma precaria, con argumentos débiles y con procedimientos inadecuados, y sin preocuparse de evaluar su impacto.

Pero el campo de posibilidades es mucho mayor. Debería incluir el debate sobre la clase de información que se ofrecerá a la población, cómo se llevaran a cabo las actuaciones formativas y los proyectos que impulsen la creación de nuevos espacios interculturales, cómo se creará e impulsará la convivencia en el nivel local y de barrio, en las escuelas, etc.

En una sociedad de iconos como es la nuestra, se hace especialmente importante analizar imágenes sobre la inmigración como la de la "patera", el "cayuco" o las "vallas", y lo que ellas suponen en el imaginario español. Las historias de las entradas "ilegales" a través del Estrecho de Gibraltar o de las Islas Canarias representan la categoría más frecuente de noticias sobre los inmigrantes en los medios de comunicación españoles, aun cuando, paradójicamente, la mayoría de inmigrantes indocumentados llegue a nuestro país por avión y con un visado turístico.

La insistencia en las imágenes de pateras/cayucos configura una realidad de la inmigración donde destaca la irregularidad en la que la llegan y se encuentran los extranjeros que alcanzan nuestras costas, en condiciones 
miserables y dramáticas que conmueven al que lo ve (aunque sea con un tipo de conmoción propio de la "moral del sentimiento mediático"). Asimismo asocia la inmigración a la transgresión de las leyes, a actos delictivos a pesar de la vigilancia y las barreras, y a la idea de la invasión, circunstancias todas que actúan como poderosas justificaciones de la adopción de políticas de seguridad. El inmigrante de patera/cayuco llega con todas las características simbólicas que lo convierten en indeseable y, en el mejor de los casos, en un superviviente.

Cabe preguntarse si no se está produciendo un espectáculo televisivo que hiperrepresenta una de las caras de la realidad de la inmigración, pero que, en lugar de permitir ahondar en las causas, transforma lo visible en opaco. Se da así la sensación de que se está conociendo el fenómeno a través de imágenes reales de lo que sucede, pero de hecho se está velando, ante la intensidad y el dramatismo de las imágenes, el significado de lo que está pasando, tanto de los que llegan en pateras como de la mayoría de inmigrantes que llega a través de la frontera del aeropuerto de Barajas.

\subsection{Líneas de política pública para la integración social}

Sin una mejora en el nivel de la información, sin un debate sobre las migraciones que se reflejan en los medios de comunicación, es difícil que los gobiernos, a diferentes niveles, puedan establecer las políticas adecuadas para la integración social. Por aludir a algunas líneas indispensables:

- En el mercado de trabajo, a través de la promoción de la igualdad de acceso al empleo, del desarrollo de acciones de formación, información y defensa de los derechos de los inmigrantes; y también de la lucha contra la economía sumergida.

- En el campo educativo, avanzando desde la participación escolar obligatoria de los niños hasta las buenas prácticas interculturales y de formación de adolescentes y jóvenes hijos de inmigrantes (mucho tenemos que aprender en estos temas de los fracasos de nuestros vecinos franceses).

- En el campo cultural, apostando por la interculturalidad. La vía intercultural es un modo de plantear la integración más como "reintegración" o "cointegración", en la que todos hacemos un esfuerzo por situarnos en algo nuevo, que como una llamada a renuncias unilaterales de los 
que vienen. Supone la confianza de que resulta posible crecer y enriquecernos todos en el respeto a la diferencia. Porque en el mundo de la interacción humana muy a menudo lo que fortalece a una parte es bueno para el conjunto del grupo.

- En el de la participación ciudadana buscando eficazmente la equiparación con los autóctonos en cuanto derechos y deberes -la ciudadanía-y potenciando el movimiento asociativo de los inmigrantes (de acuerdo con el principio de subsidiariedad).

Tras lo dicho, es importante añadir que incluso si los gobiernos aprueban medidas políticas bien orientadas hacia procesos de integración social, tendrán enormes dificultades para llevarlas a la práctica sin el respaldo de una cultura pública sobre la que se sustenten tales decisiones políticas concretas.

Si la primera necesidad es una buena información y un intercambio comunicativo fluido, no es menos importante tomar conciencia de que los procesos sociales de la inmigración tienen sus propias dinámicas: por eso no está en nuestra mano, ni siquiera si todos los países de la Unión Europea fuéramos a una (cosa que, aunque deseable, se atisba difícil de lograr), regularla a nuestro gusto ni ahorrarnos los desequilibrios transitorios que la inmigración puede causar. Queremos tener todo controlado, siempre desde la lógica de nuestro propio interés, pero olvidamos que las transformaciones sociales de las que estamos tratando no son cuestión de días ni siquiera de meses.

Como los hechos son muy tozudos, es imprescindible conocerlos bien, respetando su realidad y no haciendo brindis al sol, por bien intencionados que estos puedan estar. Esto apoya aun más, si cabe, la necesidad de conjugar ética y política para afrontar el apasionante reto para el conjunto de la sociedad al que, a falta de mejor palabra, seguimos llamando integración. 